\title{
Rutting Resistance of HMA Rehabilitated with Micro-Surfacing
}

\author{
Arbia Garfa $^{1 *}$, Alan Carter ${ }^{1}$, Anne Dony ${ }^{2}$ \\ ${ }^{1}$ École de Technologie Supérieure, ETS, Montréal, Canada \\ ${ }^{2}$ Ecole Spécial des travaux publics, ESTP, Paris, France \\ Email: *agarfa2013@gmail.com
}

How to cite this paper: Garfa, A., Carter, A. and Dony, A. (2018) Rutting Resistance of HMA Rehabilitated with Micro-Surfacing. Open Journal of Civil Engineering, 8, 245-255. https://doi.org/10.4236/ojce.2018.82019

Received: January 3, 2018

Accepted: June 26, 2018

Published: June 29, 2018

Copyright (c) 2018 by authors and Scientific Research Publishing Inc. This work is licensed under the Creative Commons Attribution International License (CC BY 4.0).

http://creativecommons.org/licenses/by/4.0/

\begin{abstract}
The work presented here is a study on the measurement and prediction of the rutting resistance of previously rutted asphalt mixes rehabilitated with a layer of micro-surfacing manufactured with virgin and recycled aggregates at different stages of aging. The experimental procedure consisted of rutting tests on hot mix asphalt slabs already degraded and repaired with virgin and recycled micro-surfacing. Then, the evolution of the behavior of micro-surfacing cast on the hot mix asphalt slabs is observed according to loading cycles of the pavement rutting tester MLPC. Before rutting tests, slabs are subjected to 24 hours at $50^{\circ} \mathrm{C}$ and aged for 2 days and 5 days at $85^{\circ} \mathrm{C}$ in the oven. The results showed rutting percentages of $6.3 \%$ for hot mix asphalt slabs aged for 2 days and $7.2 \%$ for 5 days. These hot mix slabs repaired with virgin micro-surfacing have rutting percentage of about $9.2 \%$ for 2 days of aging and $6.5 \%$ for 5 days of aging. While, the HMA slabs repaired with recycled micro-surfacing have rutting percentage of about $8.1 \%$ for 2 days of aging and $5.9 \%$ for 5 days of aging. These results allowed the development of a prediction model based essentially on three predictor variables including cycle number, rutting state and percentage of water in the micro-surfacing material. The developed model shows a strong correlation between the predicted rutting values and the rutting values measured with the MLPC rut tester. Thermal aging in oven has a positive impact on the resistance to permanent deformation of new asphalt mixes and those rehabilitated with micro-surfacing. The parameters of rutting state and contribution water are significant in the rutting prediction model, while the cycle number remains a non-significant parameter in the model but determinant.
\end{abstract}

\section{Keywords}

HMA, RAP, Micro-Surfacing, Rutting, Aging 


\section{Introduction}

Pavement maintenance can be considered as a method using a long-term preservation strategy that improves pavement performance with an integrated and cost-effective set of practices that extend pavement life, improve safety and meet expectations of motorists [1]. Due to the various deterioration, it is important that the road infrastructure management agencies use the best method of maintenance at the best time [2]. Among the existing techniques of maintenance, a popular one is micro-surfacing. It has been argued that this technique presented a solution to correct slight defects related to small radius rutting [3]. However, it must be applied in several layers. Robati et al. [3] have shown that micro-surfacing with a coarse particle size are less susceptible to rutting than micro-surfacing manufactured with a fine particle size. Studies realized by Robati et al. [4] have also demonstrated that micro-surfacing mixtures formulated with 100\% RAP meet the specifications of the ISSA TB 147 (Multilayer Loaded Wheel Test [5]), while micro-surfacing manufactured with RAS shows a decrease resistance to rutting if the percentage of RAS exceeds $10 \%$. Recent research has been carried out in order to compare the performances of two types of cold surface coatings, namely micro-surfacing and slurry seal and their ability to correct defects caused by the rutting phenomenon [6]. For both materials, degradation caused by abrasion, or the loss of aggregates was observed for both types of treatments after 3 years of service. It is important to state that even if the micro-surfacing can be used to rehabilitate defective pavement with small radius ruts, they cannot correct large radius, exceeding a few decimeters, deformation [7].

In this study, we evaluated the effectiveness of the micro-surfacing type III material to repair the rutting deformation on the pavement. To do this, we evaluated the rutting resistance of a $0-10 \mathrm{~mm}$ hot mix asphalt (HMA), named ESG-10, before rehabilitating it with micro-surfacing. The objective is to evaluate the rutting resistance of HMA with and without micro-surfacing and different curing and aging conditions, and to model the rutting resistance of a HMA rehabilitated with micro-surfacing.

In this paper, we discuss the results of a rut resistance measurement study carried out with the MLPC rut tester on the HMA slabs considered separately and the HMA slabs coated with virgin micro-surfacing and others with micro-surfacing formulated with RAP (50\% of the aggregates by weight). To simulate the site conditions, it should be noted that hot-mix asphalt plates alone, before being coated with micro-surfacing, undergo a rutting test (30,000 cycles).

This work was carried out with two different materials, a reference micro-surfacing made with virgin aggregates, and a recycled micro-surfacing, under well-defined curing and aging conditions.

\section{Material and Methods}

The experimental approach of this work was carried out in two complementary parts. The first part consists of performing rutting tests on hot mix asphalt slabs 
already rutted and repaired with a layer of micro-surfacing formulated with virgin aggregates. The second part consists of using micro-surfacing formulated with RAP to repair the rutted slabs.

A preliminary rutting test (same experimental steps as HMA+ micro-surfacing) is carried out on the HMA slabs considered as reference. Then, the evolution of the micro-surfacing cast on the hot mix asphalt slabs is observed according to the loading cycles.

\subsection{Mix Design}

The materials used in this study, as well as their origin and composition, are presented in Table 1.

During mix design, mixing begins with a pre-wetting of dried sand in oven to obtain an initial water content of $3.5 \%$ (in order to better control the parameters during formulation) to have a homogeneous mixture. A rest period of $30 \mathrm{mi}-$ nutes is observed to ensure homogeneous water absorption. Parallel to this step, the mixture of emulsion, water and adhesion agent is carried out in a container. After the rest period, the cement is added to the sand before mixing manually for 40 seconds with the liquid part (emulsion, water and adhesion agent). For the manufacture of recycled micro-surfacing, a mix design with 50\% RAP has been determined, and glass fibers were added to improve the cohesion between recycled binder and aggregates.

In order to validate the formulation of the micro-surfacing, several trials have been carried out, and the mixtures were evaluated with the cohesion test, the abrasion test, the mini rutting test and the Hilt Cohesion Test [8] [9].

For the Hot mix asphalt, a classical $10 \mathrm{~mm}$ surface course mix is used in this study, a standard bitumen of PG 70 - 28 was used. The maximum density of the mix is 2.903 with a binder content of 5.1.

Table 1. Materials used for micro-surfacing mixtures.

\begin{tabular}{|c|c|}
\hline Materials & Description \\
\hline Virgin aggregates & Quartzite sandstone with a continuous gradation $(0-5 \mathrm{~mm})$ \\
\hline Bitumen Emulsion & $\begin{array}{l}\text { A quick setting cationic bitumen emulsion } \\
\text { (60\% binder content and } 40 \% \text { water content) } \\
\text { named CQS-1HP, complying with ASTM standards; }\end{array}$ \\
\hline ADP1 & $\begin{array}{l}\text { An adhesion agent specific for micro-surfacing, containing } \mathrm{N} \text {-tallow } \\
\text { propylene polyamines mixed with hydrochloric acid and dispersed in } 10 \% \\
\text { of water by mass. Its purpose is to control the breaking of the emulsion; }\end{array}$ \\
\hline Cement & CM II 32.5 R cement, to control the breaking of the emulsion; \\
\hline $\begin{array}{l}\text { Reclaimed Asphalt } \\
\text { Pavement (RAP) }\end{array}$ & $\begin{array}{c}\text { The RAP has the same gradation as the virgin aggregates }(0 / 5 \mathrm{~mm}) \\
\text { with a bitumen content of } 4.6 \% \text {; }\end{array}$ \\
\hline Glass fiber & $\begin{array}{l}\text { Glass fibers from the United States. These fibers were used in recycled } \\
\text { Micro-surfacing manufactured with more than } 20 \% \text { of RAP in order to } \\
\text { improve the cohesion between the binder and aggregate. The content of } \\
\text { fiber is of } 0.1 \% \text { and the length of the staple fibers is about } 1 \mathrm{~mm} \text {. }\end{array}$ \\
\hline
\end{tabular}




\subsection{Manufacturing Process of Rutted HMA Rehabilitated by Micro-Surfacing}

The rutting phenomenon is influenced by several parameters: temperature, the duration of exposure to stresses, and the binder film thickness [10].

In this study, $50 \mathrm{~mm}$ thick HMA slabs were compacted with the LPC slab compactor to obtain an air voids content of $5 \%$. The HMA were subjected to rutting cycles before being rehabilitated with micro-surfacing in order to simulate site's conditions. Once the micro-surfacing was installed, the rehabilitated HMA slabs were fast cured in an oven for 24 hours at $50^{\circ} \mathrm{C}$, in order to evacuate water and volatile fractions. Afterwards, the slabs are left at room temperature to stabilize, and they are weighted to measure the loss of mass (loss of water). Generally, a constant mass is reached after the first day.

After this step, the rehabilitated slabs were placed in a draft oven at $85^{\circ} \mathrm{C}$, for a period ranging from 1 to 5 days in order to simulate the evolution of the thermal aging. The thermal aging protocol was inspired by work carried out in the IRC laboratory [9]. The curing and aging temperature were determined on the basis of previous publications [11].

\subsection{Rutting Tests}

The rutting test with the LPC rut tester (Figure 1) is a simulation test which consists in applying a $5 \mathrm{kN}$ load with a wheel inflated to $0.6 \mathrm{MPa}$ on the sample at $60^{\circ} \mathrm{C}$, for 30,000 cycles at a frequency of $1 \mathrm{~Hz}$ [10].

Repeated wheel passage leads to the formation of a rut whose depth is the average of the rut depth measured at 15 points on the surface. During the tests, three types of structures were tested: the first one was HMA plate alone. The second one is the HMA slabs rehabilitated by a layer of micro-surfacing formulated with virgin aggregates, and the third one is the HMA rehabilitated with a layer of micro-surfacing formulated with RAP.

The complex (HMA and Micro-surfacing) plate has a total thickness of $50 \mathrm{~mm}$ with a micro-surfacing thickness of about $17 \mathrm{~mm} \pm 1 \mathrm{~mm}$. The small variations

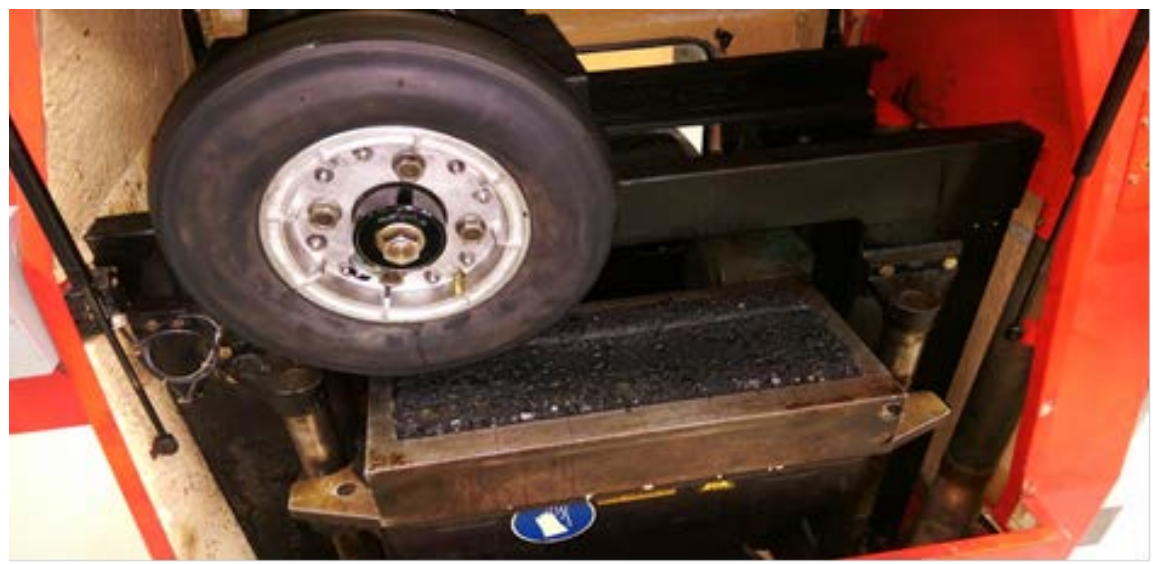

Figure 1. LPC rut tester. 
in the thicknesses of the micro-surfacing are due to the differences in the rut depths of the HMA slabs before rehabilitation. In order to have $50 \mathrm{~mm}$ thick slabs, the HMA rutted slab were saw in their thicknesses to around $33 \mathrm{~mm}$ before being covered with micro-surfacing.

The evolution of the rut depths are monitored and measured as a percentage of the initial thickness of the material in function of the number of loading cycles. Initially, rutting tests were carried out on three series of HMA slabs (Table 2). All this slabs of HMA were used as reference. Rutting tests were carried out on these slabs at $60^{\circ} \mathrm{C}$.

The second part of tests consisted of casting micro-surfacing on the hot-mix asphalt slabs and then carrying out the same process of curing/aging on the complex (HMA + virgin micro-surfacing) (Figure 2). Then, the rutting tests were carried out on these at $60^{\circ} \mathrm{C}$ (Figure 2). The same process is applied for the third type of structure HMA + recycled micro-surfacing.

\section{Results and Analysis}

The results are separated into two parts. First, the rutting results on the reference slabs are presented, before analyzing the results obtained on the rehabilitated

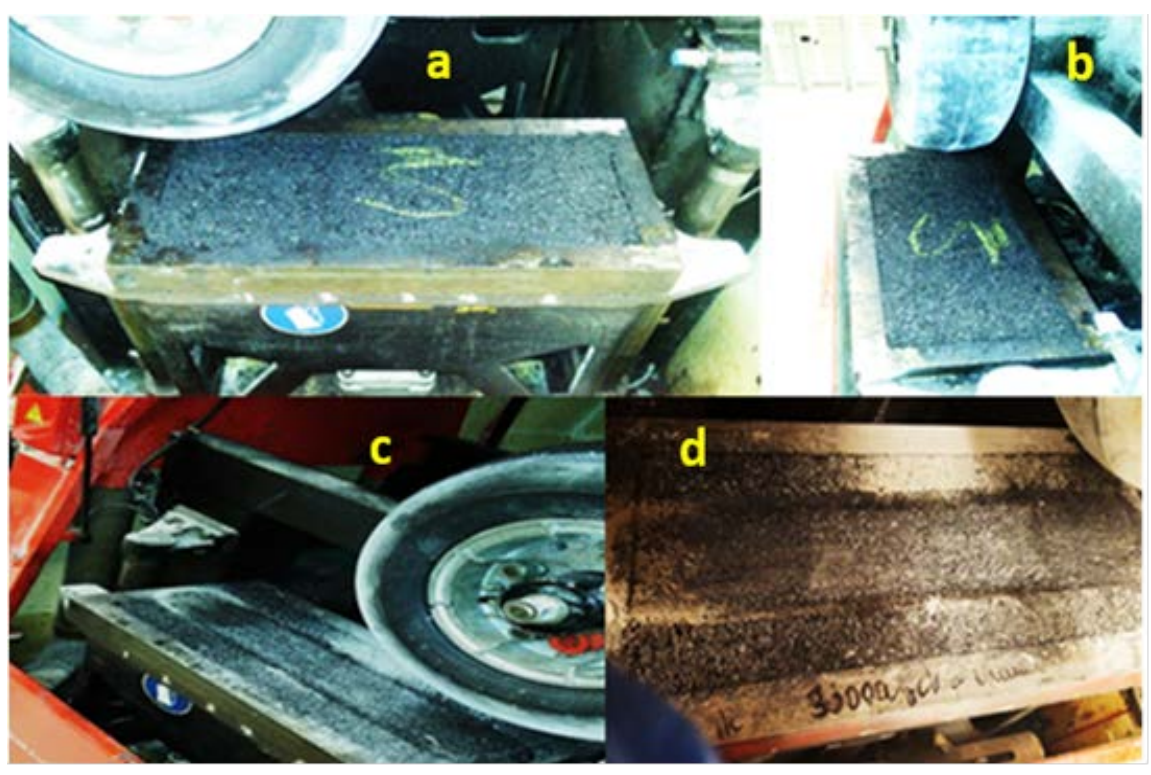

Figure 2. Rutted slabs of HMA rehabilitated with Micro-surfacing before and after rutting test (30,000 cycles) (a) Plate of HMA before rutting; (b) Plate of HMA before rutting; (c) Plate of HMA after 10,000 rutting cycles; (d) Plate of HMA after 30,000 rutting cycles.

Table 2. Conditions of rutting test for HMA samples.

\begin{tabular}{cc}
\hline Samples & Conditions of tests \\
\hline HMA 1 & Cured at $50^{\circ} \mathrm{C}$ for $24 \mathrm{~h}$ \\
HMA 2 & Cured at $50^{\circ} \mathrm{C}$ for $24 \mathrm{~h}$ and aged at $85^{\circ} \mathrm{C}$ for 2 days \\
HMA 3 & Cured at $50^{\circ} \mathrm{C}$ for $24 \mathrm{~h}$ and aged at $85^{\circ} \mathrm{C}$ for 5 days \\
\hline
\end{tabular}


slabs. Afterwards, the modeling of the behavior is shown.

\subsection{Rutting Test on HMA}

As expected, the analysis of the impact of aging on the rutting resistance of the asphalt mixes shown in Figure 3 shows that the longer the aging, the higher the rutting resistance is. Indeed, the aging carried out at $85^{\circ} \mathrm{C}$ did results in an accelerated oxidation of the binder. These phenomena are the same that are observed in the PAV and RTFOT aging processes [10]. However, there is no great difference between the resistance to rutting of the hot mix asphalt plates aged for 2 days and 5 days.

\subsection{Rutting Test on the Complex Structure HMA + Micro-Surfacing}

The rut depth results are shown in Figure 4 (slabs rehabilitated with virgin micro-surfacing) and Figure 5 (slabs rehabilitated with recycled micro-surfacing). The first thing to note on both figures is that from 0 to 30,000 cycles, only the HMA slabs are tested. At 30,000 cycles, the slabs are rehabilitated, which is why the rut depth goes down to zero.

As it can be seen from Figure 4 and Figure 5, the rutting resistance of ESG-10 mixes without micro-surfacing increase with the curing and aging times. The same trend is observed when micro-surfacing is added on top of the ESG-10 mixes. Also, by addition of micro-surfacing, the rutting resistance of ESG-10 mixes was improved. Figure 5 also shows that the rutting resistance of ESG-10 mixes is further improved with the addition of micro-surfacing mixes which consists of $50 \%$ RAP as the aggregates in micro-surfacing mixes.

We believe that the rutting resistance is improved due to the existence of aged bitumen in both ESG-10 and micro-surfacing mixes. Also, the rutting resistance is further improved by using the $50 \% \mathrm{RAP}$ as the aggregates in the micro-surfacing. This can be explained by the existence of high stiffness (very low penetration) of the RAP binder.

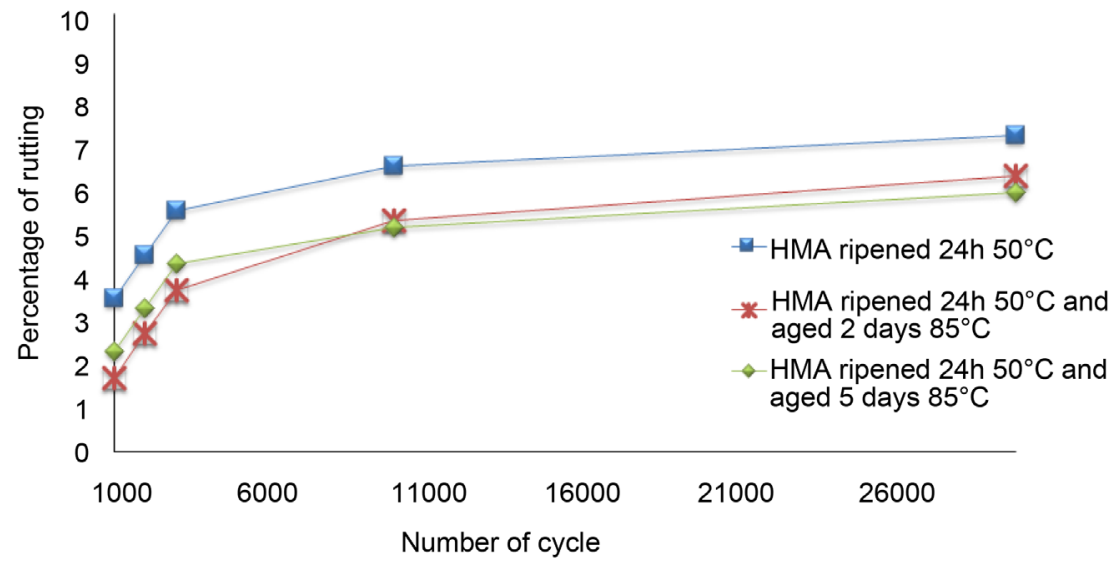

Figure 3. Impact of aging on HMA in terms of resistance to rutting. 


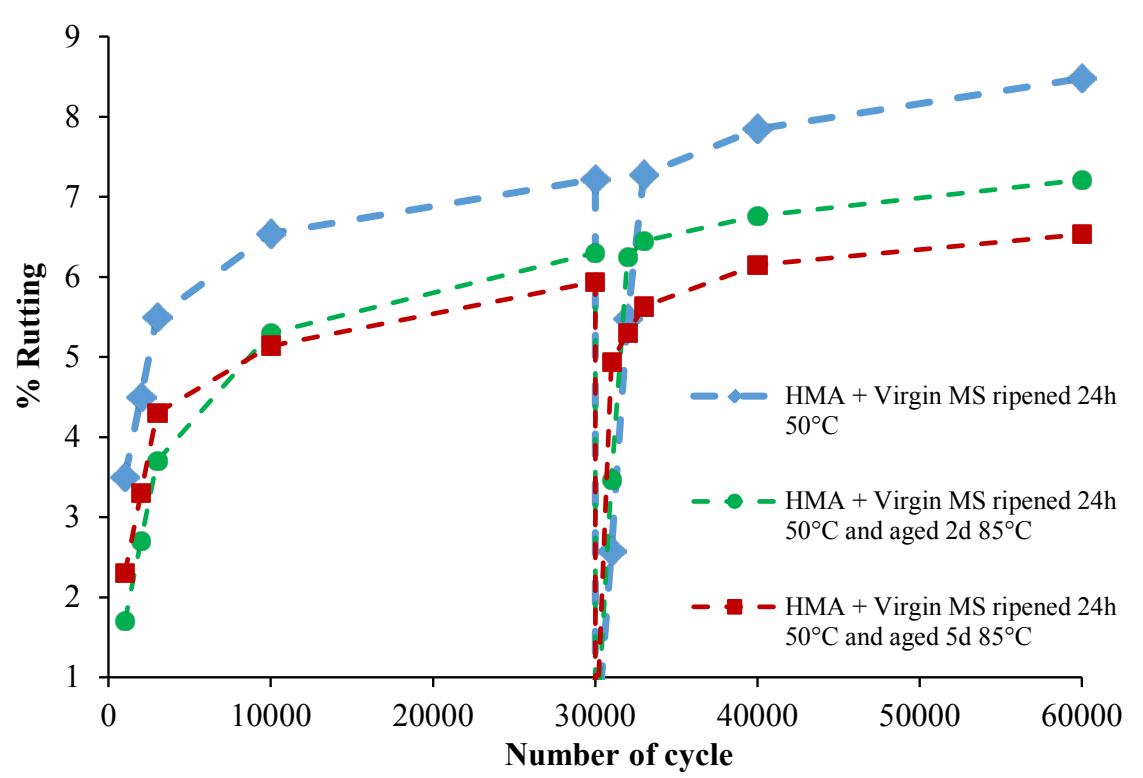

Figure 4. Impact of aging on HMA/ virgin micro-surfacing in terms of resistance to rutting.

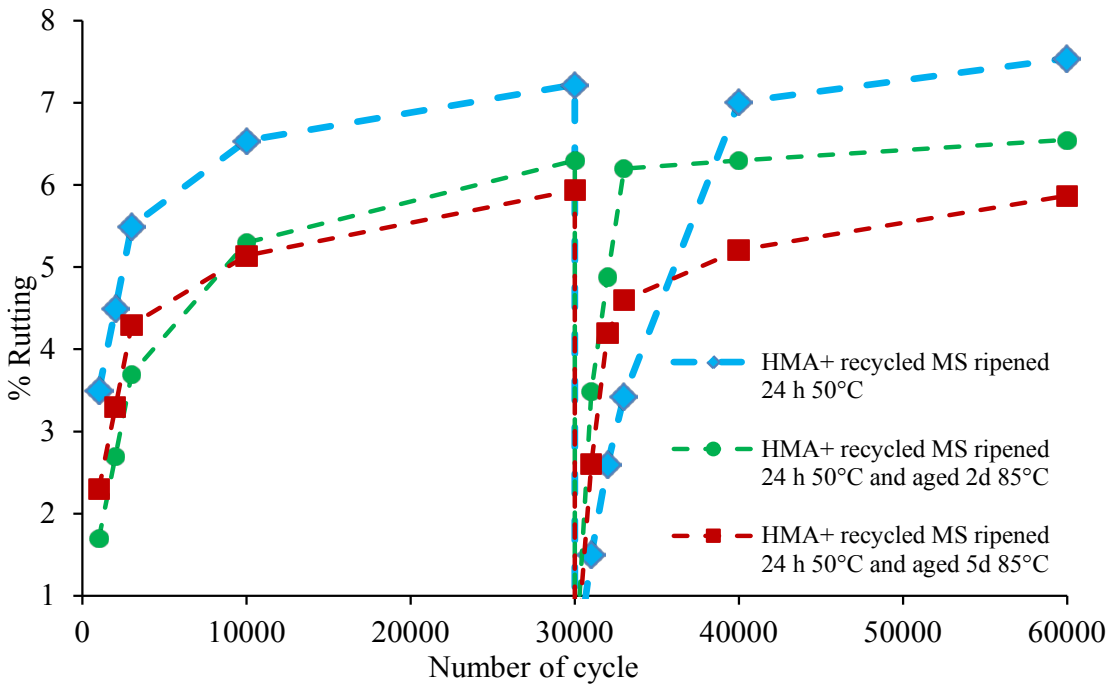

Figure 5. Impact of aging on HMA/ recycled micro-surfacing in terms of resistance to rutting.

The complex structure HMA/virgin micro-surfacing and HMA/recycled micro-surfacing have a deformation memory due to the initial rutting of the asphalt plate. Hence, a higher resistance to rutting was observed for the complex structure HMA/virgin micro-surfacing and HMA/recycled micro-surfacing. Initially, the micro-surfacing fills the initial ruts of the slabs, then it brings a reinforcement of $15-\mathrm{mm}$ thick allowing the whole structure to perform better. It should be noted however that it is necessary that micro-surfacing, conforming to the specifications of the ISSA, do not undergo a heat wave before being well stabilized, since it would results in a structure highly sensitive to rutting. 
All tested slabs in this study meet the requirements of NF EN 13108-1 standard since all the complex HMA/virgin micro-surfacing have rutting percentages of less than $10 \%$ to 30,000 cycles.

\subsection{Prediction of the Rutting of the HMA/Micro-Surfacing Complex}

Statistically, the validation of the model will be carried out through the adjusted coefficient of determination $R_{a}^{2}$ and the ratio between the standard error $S_{e}$ and the standard deviation $S_{r}$. These parameters are defined by Equations (1) (2) and (3):

$$
\begin{aligned}
& S_{e}=\sqrt{\frac{\sum(Y-\hat{Y})^{2}}{x-k}} \\
& S_{y}=\sqrt{\frac{\sum(Y-\bar{Y})^{2}}{x-1}}
\end{aligned}
$$

where $\mathrm{x}$ is sample size; $k$ is the number of independent variables in the model; $Y$ : values tested; $\hat{Y}$ : predicted values and $\bar{Y}$ is the mean value of the measured rut depth. The lowest the value of $S_{e} / S_{y}$ the greater the prediction [12] [13]. The coefficient of determination $R^{2}$ is defined by Equation (3):

$$
R_{a}^{2}=1-\frac{(x-1) \times\left(1-R^{2}\right)}{x-k-1}
$$

\section{Model Development}

Analysis of the correlation matrix presented in Table 3 shows that the percentage of virgin aggregate (sand), the percentage of cement and the curing time are not significant with respect to the percentage of rutting. Indeed, they have low correlation coefficients and $\mathrm{P}>0.05$. Thus, in the prediction of the percentage of rutting, these parameters will not be taken into account.

The prediction parameters considered are the number of cycles, the percentage of added water, the percentage of bituminous emulsion, the percentage of adhesion agent, filler, and fiber. Analysis of the linear regression showed that the statistical calculation can't estimate the percentage of rutting according to the percentage of bitumen emulsion, adhesion agent, RAP, fiber and filler. Those parameters are not considerate by the prediction model. Only three variables are selected, including the number of cycles, the rutting state before rehabilitation and the percentage of added water. Hence the development of the model (Equation (4)):

$$
\begin{aligned}
\operatorname{Rutting}(\%)= & -1.10-(0.000024 \times \text { Number of cycle }) \\
& +(0.420 \times \text { Water }(\%))+(0.991 \times \operatorname{HMArutting}(\%))
\end{aligned}
$$

Figure 6 shows a strong correlation between the predicted rutting values and the measured rutting values measured with the LPC rut tester. Indeed, a strong 
Table 3. Correlation matrix.

\begin{tabular}{|c|c|c|c|c|c|c|c|c|c|c|c|}
\hline & $\begin{array}{c}\text { Number of } \\
\text { cycle }\end{array}$ & Sand (\%) & $\begin{array}{c}\text { Added } \\
\text { Water } \\
(\%)\end{array}$ & $\begin{array}{c}\text { Bitumen } \\
\text { Emulsion (\%) }\end{array}$ & $\begin{array}{c}\text { Adhesion } \\
\text { Agent } \\
(\%)\end{array}$ & $\begin{array}{l}\text { Cement } \\
(\%)\end{array}$ & $\begin{array}{l}\text { t RAP } \\
(\%)\end{array}$ & $\begin{array}{c}\text { Filler } \\
(\%)\end{array}$ & $\begin{array}{l}\text { Fiber } \\
(\%)\end{array}$ & $\begin{array}{l}\text { Curing } \\
\text { time }\end{array}$ & $\begin{array}{l}\text { Rutting } \\
\text { state }\end{array}$ \\
\hline \multirow{2}{*}{$\begin{array}{l}\text { Number } \\
\text { of cycle }\end{array}$} & 1.000 & & & & & & & & & & \\
\hline & 0.000 & & & & & & & & & & \\
\hline \multirow{2}{*}{ Sand (\%) } & -0.054 & 1.000 & & & & & & & & & \\
\hline & 0.709 & 0.000 & & & & & & & & & \\
\hline \multirow{2}{*}{ Added Water (\%) } & 0.054 & -1.000 & 1.000 & & & & & & & & \\
\hline & 0.709 & * & 0.000 & & & & & & & & \\
\hline Bitumen Emulsion & 0.054 & -1.000 & -1.000 & 1.000 & & & & & & & \\
\hline (\%) & 0.709 & * & * & 0.000 & & & & & & & \\
\hline \multirow{3}{*}{$\begin{array}{c}\text { Adhesion Agent } \\
(\%)\end{array}$} & 0.054 & -1.000 & -1.000 & -1.000 & 1.000 & & & & & & \\
\hline & 0.709 & * & * & * & 0.000 & & & & & & \\
\hline & * & * & * & * & * & 1.000 & & & & & \\
\hline Cement (\%) & * & * & * & * & * & 0.000 & & & & & \\
\hline \multirow{2}{*}{ RAP (\%) } & 0.054 & -1.000 & -1.000 & -1.000 & -1.000 & * & 1.000 & & & & \\
\hline & 0.709 & * & * & * & * & * & 0.000 & & & & \\
\hline \multirow{2}{*}{ Filler (\%) } & 0.054 & -1.000 & -1.000 & -1.000 & -1.000 & * & -1.000 & 1.000 & & & \\
\hline & 0.709 & * & * & * & * & * & * & 0.000 & & & \\
\hline \multirow{2}{*}{ Fiber (\%) } & 0.054 & -1.000 & -1.000 & -1.000 & -1.000 & * & -1.000 & -1.000 & 1.000 & & \\
\hline & 0.709 & * & * & * & * & * & * & * & 0.000 & & \\
\hline \multirow{2}{*}{ Cirng Time } & -0.064 & 0.023 & -0.023 & -0.023 & -0.023 & * & -0.023 & $3-0.023$ & -0.023 & 1.000 & \\
\hline & 0.657 & 0.873 & 0.873 & 0.873 & 0.873 & * & 0.873 & 0.873 & 0.873 & 0.000 & \\
\hline \multirow{2}{*}{ Rutting State } & 0.774 & -0.081 & 0.081 & 0.081 & 0.081 & * & 0.081 & 0.081 & 0.081 & -0.240 & 1.000 \\
\hline & 0.000 & 0.570 & 0.570 & 0.570 & 0.570 & * & 0.570 & 0.570 & 0.570 & 0.090 & 0.000 \\
\hline \multirow{2}{*}{$\begin{array}{l}\text { Percentage of } \\
\text { rutting }\end{array}$} & 0.528 & -0.333 & 0.333 & 0.333 & 0.333 & * & 0.333 & 0.333 & 0.333 & -0.514 & 0.757 \\
\hline & 0.000 & 0.017 & 0.017 & 0.017 & 0.017 & * & 0.017 & 0.017 & 0.017 & 0.000 & 0.000 \\
\hline
\end{tabular}

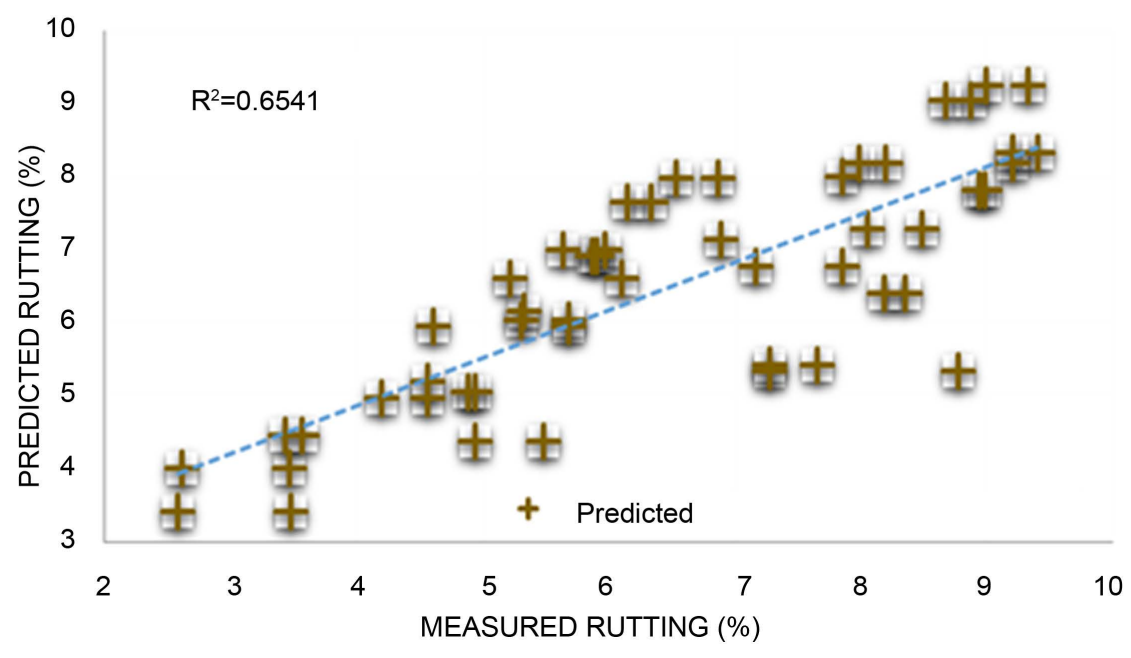

Figure 6. Predicted rutting vs Measured rutting.

adjusted coefficient of determination of $R^{2}=0.65$ is obtained with an average dispersion of $S_{e} / S_{y}=0.73$.

The Analysis of the variance (Table 4) showed that the rutting state before rehabilitation and the amount of added water are the most significant parameters in the rutting prediction model. The analysis of the variance also shows that the variable rutting state of the pavement has a p-value more significant than the 
Table 4. Variance analysis of model prediction variables.

\begin{tabular}{cccccc}
\hline Source & $\begin{array}{c}\text { Liberty } \\
\text { degree }\end{array}$ & $\begin{array}{c}\text { Sum of } \\
\text { Adjusted } \\
\text { squared value }\end{array}$ & $\begin{array}{c}\text { Adjusted } \\
\text { squared average } \\
\text { value }\end{array}$ & F-value & P-value \\
\hline $\begin{array}{c}\text { Regression } \\
\text { Number of cycle } \\
\text { MLPC }\end{array}$ & 3 & 123.713 & 41.2375 & 29.60 & 0.000 \\
Water (\%) & 1 & 1.451 & 1.4511 & 1.04 & 0.313 \\
Pavement rutting & 1 & 13.930 & 13.9305 & 10.00 & 0.003 \\
$\quad$ Error & 47 & 53.390 & 53.3903 & 38 & 0.000 \\
$\begin{array}{c}\text { Inadequacy of } \\
\text { adjustement }\end{array}$ & 24 & 65.484 & 1.3903 & - & - \\
Pure error & 23 & 3.820 & 0.166 & - & - \\
Total & 50 & 189.196 & - & - & - \\
\hline
\end{tabular}

variable percentage of added water. Thus, the parameter "added water" influences less the behaviour of the model. The cycle number is the least significant parameter of the model, its p-value is not significant. However, it remains an important parameter in the prediction of rutting.

\section{Conclusions}

This article showed that thermal aging in oven has an impact on the resistance to the permanent deformation of bituminous mixes. Indeed, the study of the influence of aging in terms of resistance to rutting of hot mix asphalt showed that their resistance to rutting increased with the aging. Tests done on the complex structure HMA/Micro-surfacing allowed us to show that the longer the aging of the hot-mix asphalt slabs rehabilitated by micro-surfacing is, the higher their resistance to rutting becomes, provided that the HMA coated by micro-surfacing is well stabilized with implementation rather far from the summer heat wave.

These phenomena are essentially due to the oxidation of the bituminous binders contained in these materials and leading them to harden. In addition, a memory phenomenon (summation) of the initial rutting of the bituminous mix is observed. Indeed, the secondary rutting observed on the complex structure HMA/Microsurfacing is more important than the initial rutting of the HMA slab.

The study also showed that the rut depth before rehabilitation (rutting state) and input water (added water) percentage parameters are significant in the rutting prediction model, while the cycle number remains a non-significant parameter in the model but determinant. The regression analysis showed a strong correlation between the rutting values predicted by the model and the values measured in the laboratory with the LPC rut tester.

\section{Acknowledgements}

To Probinord, LCMB and ETSP. 


\section{References}

[1] Federal Highway Administration (2005) Memorandum on Pavement Preservation Definitions. International Slurry Surfacing Association. http://www.slurry.org

[2] Uzarowski, L. and Bashir, I. (2007) A Rational Approach for Selecting the Optimum Binder Pavement Preventive and Rehabilitation Treatments-Two Practical Examples from Ontario. Annual Conference of the Transportation Association of Canada, Saskatoon.

[3] Robati, M., Carter, A. and Perraton, D. (2013) Evaluation of Test Methods and Selection of Aggregate Grading for Type III Application of Micro-Surfacing. The International Journal of Pavement Engineering and Asphalt Technology (PEAT), 14, 11-35. https://doi.org/10.2478/ijpeat-2013-0001

[4] Robati, M., Carter, A. and Perraton, D. (2013) Incorporation of Reclaimed Asphalt Pavement and Post-Fabrication Asphalt Shingles in Micro-Surfacing Mixture. Canadian Technical Asphalt Association, St. Johns, Newfoundland, Canada.

[5] International Slurry Surfacing Association (2005) Test Method for Measurement of Stability and Resistance to Compaction. Vertical and Lateral Displacement of Multilayered Fine Aggregate Cold Mixes, 1st Revision. International Slurry Surfacing Association, Design Technical Bulletins, 147. Annapolis (Md.).

[6] Kucharek, A.S., Davidson, J.K., Moore, T. and Linton, P. (2010) Performance Review of Micro Surfacing and Slurry Seal Applications in Canada. Canadian Technical Asphalt Association.

[7] Pittenger, D.M., Gransberg, D.D., Zaman, M. and Riemeraz, C. (2014) Comparative Analysis of Micro-Surfacing and Portland Cement Slurry Seal for Rut Filling. Transportation Research Board (TRB) 93rd Annual Meeting, Washington DC, 12-16 January 2014, 11 p.

[8] International Slurry Surfacing Association (2010) Micro-Surfacing Pavement Resurfacing. International Slurry Surfacing Association, Washington DC.

[9] Garfa, A., Sanou, O., Dony, A., Ziyani, L., Carter, A., Zaouali, W. and Charton, V. (2016) Effect of Aging on Binder Characteristics of Virgin and Recycled MicroSurfacing Materials. International Society for Asphalt Pavement (ISAP).

[10] Di Benedetto, H.V. and Corté, F. (2005) Matériaux (Vol. 2). (H. Science, Éd.) Lyon: Lavoisier.

[11] Central Laboratory of Bridges and Road (1987) Characterization of Modified Binders for Surface Coatings. Laboratories-Road Construction Report.

[12] Hastie, T., Tibshirani, R. and Friedman, J. (2001) The Elements of Statistical Learning; Data Mining, Inference and Prediction. Springer Verlag, New York.

[13] Nisbet, R., Elder, J. and Miner, G. (2009) Handbook of Statistical Analysis and Data Mining Applications. Academic Press, 864 p. 